\title{
Learning the fiscal theory of the price level: Some consequences of debt-management policy
}

\author{
Stefano Eusepi ${ }^{\mathrm{a}, *}$, Bruce Preston ${ }^{\mathrm{b}, \mathrm{c}}$ \\ ${ }^{a}$ Federal Reserve Bank of New York, United States \\ ${ }^{\mathrm{b}}$ Department of Economics, Columbia University, 420 West 118th St., New York, NY 10027, United States \\ ${ }^{\mathrm{c}}$ Research School of Economics, Australian National University, Australia
}

\section{A R T I C L E I N F O}

\section{Article history:}

Available online 16 September 2011

\section{JEL Classification:}

E32

D83

D84

\section{Keywords:}

Debt management policy

Maturity structure

Monetary policy

Expectations stabilization

\begin{abstract}
A B S T R A C T
Eusepi, Stefano, and Preston, Bruce-Learning the fiscal theory of the price level: Some consequences of debt-management policy

This paper examines the consequences of the scale and composition of the public debt in policy regimes in which monetary policy is 'passive' and fiscal policy 'active'. This configuration of policy is argued to be of both historical and contemporary interest, in economies such as the US and Japan. It is shown that higher average levels and moderate average maturities of debt can induce macroeconomic instability for a range of policies specified as simple rules. However, interest-rate pegs combined with active fiscal policies almost always ensure macroeconomic stability. This suggests that in periods where the zero lower bound on nominal interest rates is a relevant constraint on policy design, a switch in fiscal regime is desirable. J. Japanese Int. Economies 25 (4) (2011) 358379. Federal Reserve Bank of New York, United States; Department of Economics, Columbia University, 420 West 118th St., New York, NY 10027, United States; Research School of Economics, Australian National University, Australia.
\end{abstract}

(c) 2011 Elsevier Inc. All rights reserved.

\section{Introduction}

The conventional characterization of stabilization policy is that monetary policy stabilizes inflation while fiscal policy stabilizes debt through an appropriate adjustment in current or future taxation. The

\footnotetext{
* Corresponding author.

E-mail addresses: stefano.eusepi@ny.frb.org (S. Eusepi), bp2121@columbia.edu (B. Preston).
} 
resulting equilibrium is Ricardian, so that debt-management policy has no monetary consequences. In the language of Leeper (1991) monetary policy is 'active' and fiscal policy is 'passive'.

The appropriateness of this view as a general description of policy can certainly be questioned. Both recent events and certain historical episodes adduce evidence. In response to the US financial crisis 2007-2009 many economies have found monetary policy constrained by the zero lower bound on nominal interest rates. At the same time, there has been substantial fiscal stimulus that, at least initially, was provided without overt concern for the consequences of the level of the public debt. This policy configuration can reasonably be characterized as an interest-rate peg combined with an exogenous fiscal surplus. Here monetary policy is 'passive', fiscal policy 'active', and the resulting equilibrium non-Ricardian - debt-management policy has monetary consequences.

Outside this recent episode, there is evidence of changing configurations of policy regime in the US in the post-war period that include passive monetary policy and active fiscal policy - see Davig and Leeper (2006). During the 1940s, a special case of this policy configuration was actively pursued. Called a 'bond-price support' regime, interest rates on short-term treasury bills were pegged, with fiscal policy assuming the role of active stabilization. Woodford (2001) argues that inflation data from this period are consistent with the fiscal theory of the price level. Outside the US, the Japanese economy has clearly experienced a prolonged period of low interest rates since the mid 1990s, with frequent attempts to spur economic activity through fiscal stimulus. Again, this experience seems better characterized by a policy regime with passive monetary and active fiscal policy. ${ }^{1}$

And even if such depictions of policy are deemed inappropriate, it is not implausible to think households and firms may entertain policy configurations of this kind. Indeed, Bianchi (2010) and Sims (2011) demonstrate that even if agents only maintain the possibility of an alternative regime in expectation, without that regime ever occurring, there can be important implications for dynamics. As well-known from Sargent and Wallace (1975), passive fiscal policy combined with an interest-rate peg delivers indeterminacy of rational-expectations equilibrium. Periods in which nominal interestrate policy is constrained by the zero lower bound might be periods in which expectations are particularly susceptible to drift. As such it is worth exploring the stabilization consequences of this kind of policy regime.

To this end we consider a standard New Keynesian model of the kind frequently used for monetary policy evaluation, in which agents have incomplete knowledge about the structure of the economy. Incomplete knowledge is introduced to capture uncertainty about the prevailing policy regime, a characteristic of recent policy responses during the US financial crisis, particularly given the substantial uncertainty about the scale, scope and duration of various fiscal policy initiatives. Households and firms are optimizing, have a completely specified belief system, but do not know the equilibrium mapping between observed state variables and market clearing prices. By extrapolating from historical patterns in observed data they approximate this mapping to forecast exogenous variables relevant to their decision problems, such as prices and policy variables. Because agents must learn from historical data, beliefs need not be consistent with the objective probabilities implied by the economic model. The analysis is centrally concerned with conditions under which agents can learn the underlying rational expectations equilibrium of the model. Such convergence is referred to as "expectations stabilization" or "stable expectations". A situation of unstable expectations is referred to as expectationsdriven instability.

In this environment we study the stability properties of various configurations of monetary and fiscal policy, specified as simple rules. Monetary policy is given by a Taylor-type rule for the conduct of nominal interest-rate policy as a function of some measure of inflation. Fiscal policy is given by a

\footnotetext{
${ }^{1}$ The characterization of the Japanese policy regime has been a matter of active debate. Particularly given that stabilization policy appears to have failed, at least from the perspective of delivering robust and sustainable output growth. An important issue is the treatment of long-term fiscal expectations - which would be no less important in a Ricardian characterization of dynamics. Standard models place tight structure on long-term beliefs regarding fiscal solvency. Failure to cover issued debt with appropriate future taxation will induce an adjustment in goods price to revalue public debt. That resumption of normal economic activity has not occured with little evidence of inflation in Japan questions the passive monetary and active fiscal policy assumption. However, this likely reflects the inconsistent fiscal policy framework adopted by Japanese authorities. Each fiscal expansion was soon followed with promises of consolidation. Appropriately modeling these announcement effects on household expectations remains as important future work.
} 
simple rule for the adjustment of the structural surplus in response to outstanding government liabilities. Given this policy framework, the analysis is interested in the role of the scale and composition of debt. In contrast to a rational-expectations analysis of the model, these characteristics of fiscal policy have important implications for stabilization policy under learning dynamics. We show that the average maturity of debt can constrain the set of monetary and fiscal policies that are consistent with expectations stabilization.

The source of instability derives from three model features. First, a monetary policy rule that responds to inflation, despite being 'passive'. Second, a positive steady-state debt level so that variations in government liabilities have first-order effects on consumption. Third, the average duration of debt is greater than one period, so that variations in the price of bonds affect the size of public debt. These effects combine so that moderate maturities of debt generate instability by making debt issuance more volatile when inflation expectations shift. On the one hand, in the neighborhood of rational expectations equilibrium, the price of the public debt portfolio becomes more sensitive to inflation expectations the greater the average duration of debt. This makes bond issuance more sensitive to a given shift in inflation expectations, because the quantity of issued debt depends on this price. On the other hand, as the average maturity rises, the amount of debt rolled over in any given period declines - changed bond prices pertain to a smaller fraction of issued debt. The former price effect tends to amplify, and the latter portfolio effect, dampen, the effect of inflation expectations on the evolution of debt. The net effects generate instability in aggregate demand as holdings of the public debt are perceived as net wealth. And these effects are largest for short to medium maturity debt.

The dependency of this basic insight on various parametric assumptions is explored in detail. A specific policy recommendation that emerges is that monetary policy should be conducted according to an interest-rate peg. While an analytic result is not feasible, extensive numerical analysis reveals that for all relevant regions of the parameter space, interest-rate pegs deliver stability under learning dynamics. This result holds regardless of the scale and composition of debt.

Because active fiscal policy coupled with an interest-rate peg successfully stabilizes expectations, switching to an active fiscal policy rule when the interest rate is at the zero lower bound can be an effective policy option to prevent a deflationary spiral. There are two caveats to this recommendation. First, the stability analysis has only local validity; that is the stability results hold provided agents' expectations are sufficiently close to rational expectations. A switch from a Ricardian regime with active monetary policy to an active fiscal regime coupled with an interest-rate peg requires a significant adjustment in public expectations. The success of such a policy is likely determined by the communication strategy followed by the monetary and fiscal authority, and their credibility in following announced plans.

Second, we focus on rational expectations equilibria where the policy regime remains in place indefinitely. As documented in Davig and Leeper (2006) for the US, policy regime switches are the norm. A switch to an active fiscal regime in response to hitting the zero lower bound would likely be temporary in nature. An extension of the stability analysis to regime switches is left for further research. $^{2}$

The paper proceeds as follows. Section 2 lays out the model. Section 3 describes belief structure underpinning the assumed learning dynamics. Section 4 states some benchmark properties of the model for which analytical results are available. Section 5 provides benchmark parameter assumptions. Section 6 gives results for an interest-rate rule that responds to contemporaneous inflation. Section 7 gives analogous results for a forecast-based instrument rule. Section 8 explores the robustness of conclusions to variations in the assumed belief structure. Section 9 explores the robustness of conclusions to an alternative model of decision making. Section 10 concludes.

\section{A simple model}

The following section details the model studied by Eusepi and Preston (2011). The model is similar in spirit to Clarida et al. (1999) and Woodford (2003) used in many recent studies of monetary policy.

\footnotetext{
${ }^{2}$ Branch et al. (2008) study the E-stability properties of regime switching models using learning models where only one-periodahead expectations matter. Their methodology could easily be adapted to the framework proposed in this paper.
} 
The major difference is the emphasis given to details of fiscal policy and the incorporation of near-rational beliefs delivering an anticipated utility model as described by Kreps (1998) and Sargent (1999). The analysis follows Marcet and Sargent (1989a) and Preston (2005b), solving for optimal decisions conditional on current beliefs. The discussion here only presents the implied log-linear approximation in the neighborhood of a non-stochastic steady state. For additional detail the reader is referred to Eusepi and Preston (2011).

\subsection{Aggregate demand and supply}

The model has an aggregate demand relation of the form

$$
\widehat{C}_{t}=\bar{s}_{C}^{-1} \delta\left(\hat{b}_{t-1}^{m}-\hat{\pi}_{t}+\rho \beta \widehat{P}_{t}^{m}\right)+\widehat{E}_{t} \sum_{T=t}^{\infty} \beta^{T-t}\left[\bar{s}_{C}^{-1}(1-\beta) x_{T}-\beta\left(\sigma^{-1}-\bar{s}_{C}^{-1} \delta\right)\left(\hat{\imath}_{T}-\hat{\pi}_{T+1}\right)\right]
$$

where $\widehat{C}_{t}$ is consumption, $\hat{\pi}_{t}$ inflation, $\hat{l}_{t}$ nominal interest rates, $\hat{b}_{t-1}^{m}$ holdings of the public debt in real terms, $\widehat{P}_{t}^{m}$ the price of the public debt and

$$
x_{T}=\left(\frac{\theta-1}{\theta}\right)\left(1+\gamma^{-1}\right) \hat{w}_{T}+\theta^{-1} \hat{\Gamma}_{T}-s_{\tau} \hat{\tau}_{T}
$$

denotes period after-tax income. This income in turn depends upon the real wage, $\hat{w}_{t}$, dividends, $\widehat{\Gamma}_{T}$, and lump-sum taxes, $\hat{\tau}_{T}$. All model variables are properly interpreted as log-deviations from steadystate. Household preferences are characterized by a discount factor satisfying $0<\beta<1$ and the inverse intertemporal elasticity of substitution $\sigma>0$. The remaining parameters are $s_{\tau}=\bar{\tau} / \bar{Y}$ the steady-state ratio of taxes-to-output; $\delta$ the steady-state structural surplus-to-income ratio; $\rho$ a parameter indexing the average maturity of government debt (discussed further below); and

$$
\bar{s}_{C}=\sigma \gamma^{-1}(\theta-1) \theta^{-1}+\bar{C} / \bar{Y}
$$

a composite of model primitives including the inverse Frisch elasticity of labor supply, $\gamma$, the elasticity of demand across differentiated goods, $\theta$, and the steady-state consumption-to-income ratio, $\bar{C} / \bar{Y}$. Finally, $\widehat{E}_{t}$ represents average beliefs held by households.

Aggregate supply is determined by the generalized Phillips curve

$$
\hat{\pi}_{t}=\psi\left(\hat{w}_{t}-\widehat{Z}_{t}\right)+\widehat{E}_{t} \sum_{T=t}^{\infty}(\alpha \beta)^{T-t}\left[\psi \alpha \beta\left(\hat{w}_{T+1}-\widehat{Z}_{T+1}\right)+(1-\alpha) \beta \hat{\pi}_{T+1}\right]
$$

where $\widehat{Z}_{t}$ is an aggregate technology shock which satisfies

$$
\ln \left(Z_{t}\right)=\left(1-\rho_{Z}\right) \ln (\bar{Z})+\rho_{Z} \ln \left(Z_{t-1}\right)+\varepsilon_{Z, t}
$$

where $0<\rho_{Z}<1$ and $\varepsilon_{Z, t}$ stationary disturbance. The parameter $\alpha$ satisfies the restrictions $0<\alpha<1$ and $\psi=(1-\alpha \beta)(1-\alpha) \alpha^{-1}$. In a model of Calvo price adjustment, $\alpha$ would denote the probability of a firm not being able re-set prices in any given period.

Eqs. (1) and (2) can be derived from standard microfoundations and are valid for arbitrary expectations satisfying standard probability laws. It is assumed that households and firms correctly understand their own objectives and any relevant constraints. However, in forecasting the various prices and state variables the are beyond their control but relevant to their decision problem they are assumed to have an incomplete economic model. Specifically, they are assumed to face uncertainty about the equilibrium mapping between state variables and market clearing prices. They approximate this mapping by extrapolating from historical patterns in observed data. As additional data become available the approximate model is revised. The structure of beliefs is discussed in more detail in Section 3.

The first Eq. (1) represents the aggregation of optimal consumption decisions by households, which are implications of their consumption Euler equation, intratemporal labor-leisure decision, and intertemporal budget constraint. The presence of long-horizon expectations arise from the intertemporal nature of households' consumption decisions: to allocate optimally consumption today requires the household to plan its future consumption and labor supply over time and across states of natures, 
which in turn requires forecasts of variables such as period income and interest rates. It generalizes well-known predictions of permanent income theory. The terms in the first line capture the insight that households should consume a constant fraction of financial wealth - comprising the quantity of bonds, their capital value and an adjustment for inflation. The terms in the second line capture the additional prediction that households should consume a constant fraction of expected discounted future income. In contrast to permanent income theory, this model permits time variation in real interest rates, due either to changes in nominal interest rates or inflation.

The second Eq. (2) can be derived from the aggregation of the optimal prices chosen by firms to maximize the expectation discounted flow of profits under a Calvo-style price-setting problem see Yun (1996). It is a generalized Phillips curve, specifying current inflation as depending on contemporaneous values of wages and the technology shock, and expectations for these variables and inflation into the indefinite future. The presence of long-term expectations arise due to pricing frictions embodied in Calvo pricing. When a firm has the opportunity to change its price in period $t$ there is a probability $\alpha^{T-t}$ that it will not get to change its price in the subsequent $T-t$ periods. The firm must concern itself with macroeconomic conditions relevant to marginal costs into the indefinite future when deciding the current price of its output. Future profits are also discounted at the rate $\beta$, which equals the inverse of the steady-state gross real interest rate.

The aggregation of optimal household and firm spending and pricing plans, along with goods market clearing also deliver the following aggregate relations. Given optimal prices, firms stand ready to supply desired output which determines aggregate hours as

$$
\widehat{H}_{t}=\widehat{Y}_{t}-\widehat{Z}_{t}
$$

and comes from aggregation of firm production technologies, which take labor as the only input. Wages and dividends are then determined from

$$
\begin{aligned}
& \gamma \widehat{H}_{t}=-\sigma \widehat{C}_{t}+\hat{w}_{t} \\
& \widehat{\Gamma}_{t}=\widehat{Y}_{t}-(\theta-1)\left(\hat{w}_{t}-\widehat{Z}_{t}\right),
\end{aligned}
$$

where the former is derived from the labor-leisure optimality condition of households, and the latter from the definition of firm profits. Finally, goods market clearing implies the log-linear restriction

$$
\widehat{Y}_{t}=s_{C} \widehat{C}_{t}+\left(1-s_{C}\right) \widehat{G}_{t}
$$

where $s_{C}=\bar{C} / \bar{Y}$ is the steady-state consumption-to-output ratio, and $\widehat{G}_{t}$ government purchases which satisfies

$$
\ln \left(G_{t}\right)=\left(1-\rho_{G}\right) \ln (\bar{G})+\rho_{G} \ln \left(G_{t-1}\right)+\varepsilon_{G, t}
$$

where $0<\rho_{G}<1$ and $\varepsilon_{G, t}$ stationary disturbance.

\subsubsection{Asset prices and no-arbitrage}

There are two types of government debt: one-period government debt in zero net supply with price $\widehat{P}_{t}^{s}$; and a more general portfolio of government debt, $\hat{b}_{t}^{m}$, in non-zero net supply with price $\widehat{P}_{t}^{m}$. The former debt instrument satisfies $\widehat{P}_{t}^{s}=-\hat{i}_{t}$ and defines the period nominal interest rate, the instrument of central bank monetary policy. Following Woodford (1998) and Woodford (2001) the latter debt instrument has payment structure $\rho^{T-(t+1)}$ for $T>t$ and $0 \leqslant \rho \leqslant 1$. The asset can be interpreted as a portfolio of infinitely many bonds, with weights along the maturity structure given by $\rho^{T-(t+1)}$. The advantage of specifying the debt portfolio in this way is that it introduces only a single state variable whose properties are indexed by single parameter $\rho$. Varying $\rho$ varies the average maturity of debt. For example, the case of one-period debt corresponds to $\rho=0$. A console bond corresponds to $\rho=1$.

Households' optimality conditions for holding each of the two assets provides the no-arbitrage restriction

$$
\hat{\imath}_{t}=-\widehat{E}_{t}\left(\widehat{P}_{t}^{m}-\rho \beta \widehat{P}_{t+1}^{m}\right) .
$$

Solving this relation forward and using transversality determines the price of the bond portfolio as 


$$
\widehat{P}_{t}^{m}=-\widehat{E}_{t} \sum_{T=t}^{\infty}(\rho \beta)^{T-t} \hat{\boldsymbol{l}}_{T} .
$$

The multiple-maturity debt portfolio is priced as the expected present discounted value of all future one-period interest rates, where the discount factor is given by $\rho \beta$. This expression makes evident that the average duration of the portfolio is given by $(1-\beta \rho)^{-1}$. A central focus of the analysis will be the consequences of variations in average maturity for expectations stabilization.

\subsection{Monetary and fiscal policy} rules

The central bank is assumed to implement monetary policy according to the family of interest rate

$$
\hat{\imath}_{t}=\phi_{\pi}\left[\omega \hat{\pi}_{t}+(1-\omega) \widehat{E}_{t} \hat{\pi}_{t+1}\right]
$$

where $\phi_{\pi} \geqslant 0$ and $0 \leqslant \omega \leqslant 1$ are policy parameters. In practice we study only the limiting cases $\omega=1$, corresponding to a contemporaneous inflation rule, and $\omega=0$, corresponding to an expectationsbased inflation rule. The stability properties of intermediate cases can be inferred once it is understood that, all else equal, the contemporaneous rule maximizes the stability region, while the expectationsbased rule, minimizes the stability region, with the latter a subspace of the former.

The activities of the fiscal authority are summarized by the relations

$$
\begin{aligned}
& \hat{b}_{t}=\beta^{-1}\left(\hat{b}_{t-1}^{m}-\hat{\pi}_{t}\right)+(\rho-1) \widehat{P}_{t}^{m}-\left(\beta^{-1}-1\right) \hat{s}_{t} \\
& \hat{l}_{t}=\hat{b}_{t-1}^{m}+\beta \rho \widehat{P}_{t}^{m} \\
& \hat{s}_{t}=\phi_{l} \hat{l}_{t} \\
& \hat{\tau}_{t}=s_{\tau}^{-1}\left(\delta \hat{s}_{t}+\left(1-s_{C}\right) \widehat{G}\right)
\end{aligned}
$$

which describe the evolution of total outstanding bonds - a log-linear approximation to the government's flow budget constraint; the definition of government liabilities, $\hat{l}_{t}$; tax collections specified directly in terms of the structural surplus, $\hat{s}_{t}$, with associated policy parameter $\phi_{l}>0$; and the definition of the structural surplus as the difference between lump-sum tax collections and government purchases.

This completes the description of aggregate dynamics. To summarize, the model comprises the twelve aggregate relations (1), (2), (3), (4), (5), (6), (8), (9), (10), (11), (12), (13) which determine the evolution of the variables $\left\{\widehat{P}_{t}^{m}, \hat{\pi}_{t}, \hat{l}_{t}, \hat{w}_{t}, \hat{\Gamma}_{t}, \widehat{C}_{t}, \widehat{Y}_{t}, \widehat{H}_{t}, \hat{b}_{t}, \hat{s}_{t}, \hat{l}_{t}, \hat{\tau}_{t}\right\}$ given the exogenous processes $\left\{\widehat{G}_{t}, \widehat{Z}_{t}\right\}$.

\section{Belief formation}

\subsection{Beliefs}

This section describes the learning dynamics and the criterion to assess convergence of beliefs. The optimal decisions of households and firms require forecasting the evolution of future prices - nominal interest rates, real wages, dividends, taxes and inflation - and exogenous shocks. In the benchmark case, agents are assumed to use a linear econometric model of the form

$$
\left[\begin{array}{c}
\hat{\tau}_{t} \\
\hat{\imath}_{t} \\
\hat{w}_{t} \\
\hat{\Gamma}_{t} \\
\hat{s}_{t} \\
b_{t}
\end{array}\right]=\Omega_{0}+\Omega_{1}\left[\begin{array}{c}
\hat{\pi}_{t-1} \\
\hat{\imath}_{t-1} \\
\hat{w}_{t-1} \\
\hat{\Gamma}_{t-1} \\
\hat{s}_{t-1} \\
b_{t-1}
\end{array}\right]+\Omega_{2}\left[\begin{array}{c}
\widehat{G}_{t-1} \\
\widehat{Z}_{t-1}
\end{array}\right]+e_{t}
$$


where $\Omega_{0}$ is a matrix with dimension $(6 \times 1) ; \Omega_{1}$ a matrix with dimension $(6 \times 6) ; \Omega_{2}$ a matrix of dimension $(6 \times 2)$; and $e_{t}$ a vector of regression errors. The belief structure is over-parameterized relative to the minimum-state-variable rational expectations solution, which depends only on the states $\left\{\hat{b}_{t-1}, \widehat{G}_{t-1}, \widehat{Z}_{t-1}\right\}$. While the rational expectations solution does not contain a constant, it has a natural interpretation under learning of capturing uncertainty about the steady state. For simplicity it is assumed that agents know the autoregressive coefficients of the exogenous processes for government purchases, technology and preference shocks. ${ }^{3}$

\subsection{Expectations stability}

Using (14) to substitute for expectations in (1), (2) and (8) and solving with the intratemporal conditions of the model delivers the actual data generating process

$$
u_{t}=\Gamma_{1}(\Omega) q_{t-1}^{\prime}+\Gamma_{2}(\Omega) \varepsilon_{t}
$$

where $\Omega=\left[\Omega_{0} \Omega_{1} \Omega_{2}\right]$ be the matrix of coefficients to estimate, $u_{t}=\left(\hat{\pi}_{t}, \hat{l}_{t}, \hat{w}_{t}, \hat{\Gamma}_{t}, \hat{s}_{t}, \hat{b}_{t}\right)$ and $q_{t}=\left(1, u_{t}, \widehat{G}_{t}, \widehat{Z}_{t}\right) . \Gamma_{1}(\hat{\Omega})$ and $\Gamma_{2}(\hat{\Omega})$ are nonlinear functions of agents' model parameters. The stability under learning depends on the interaction between agents' model $(\Omega)$ and the true model $\left(\Gamma_{1}(\Omega)\right)$. The two models coincide only at the rational expectations equilibrium $\left(\Omega^{R E}\right)$. Marcet and Sargent (1989b) and Evans and Honkapohja (2001) show that conditions for convergence are characterized by the local stability properties of the associated ordinary differential equation

$$
\frac{d(\hat{\Omega})}{d \tau}=\Gamma_{1}(\Omega)-\Omega
$$

where $\tau$ denotes notional time. The rational expectations equilibrium is said to be expectationally stable, or E-Stable, if this differential equation is locally stable in the neighborhood of the rational expectations equilibrium where $\Gamma_{1}\left(\Omega^{R E}\right)=\Omega^{R E}$. Because beliefs are over parameterized relative to the rational expectations equilibrium local stability is sometimes referred to as strong E-Stability. See Evans and Honkapohja (2001) for further discussion.

\section{Benchmark implications}

To anchor ideas and provide a comparative benchmark, it is useful to state model properties under rational expectations. In this paper we focus on a particular policy configuration where fiscal policy is 'active' and monetary policy is 'passive' in the sense of Leeper (1991).

Our motivation for doing so reflects both historical and contemporary examples of such policy configurations. For example, Davig and Leeper (2006) provide evidence of ongoing regime changes in policy - including regimes in which monetary policy is passive and fiscal policy active. Furthermore, many industrialized countries have recently experienced the constraint of the zero lower bound on nominal interest rates. And while active fiscal policy and passive monetary policy is not the same as passive fiscal policy combined with active monetary policy subject to the zero lower bound constraint, it is nonetheless useful to analyze such configurations of policy. Periods during which nominal interest rates are pegged are times when expectations might be particularly susceptible to drift - for reasons outlined in Sargent and Wallace (1975) - and given considerable uncertainty about the conduct of fiscal policy during the crisis, it is not unreasonable to suppose agents might have viewed policy to be configured in this way. Moreover, it may prove desirable to have fiscal policy be conducted in

\footnotetext{
3 The assumption that autocorrelation coefficients are known to agents are not too important for the results of the paper. The Estability conditions are independent of this assumption because given observations on each disturbance, asymptotically the autocorrelation coefficients are recovered with probability one using linear regression. Assuming these parameters are known serves to understate variation for a given primitive shocks.

${ }^{4}$ Standard results for ordinary differential equations imply that a fixed point is locally asymptotically stable if all eigenvalues of the Jacobian matrix $D[\Gamma(\Omega)-(\Omega)]$ have negative real parts (where $D$ denotes the differentiation operator and the Jacobian is understood to be evaluated at the relevant rational expectations equilibrium).
} 
an active manor given the constraint of the zero lower bound. If so, understanding the associated stability properties has clear merit.

Proposition 1. Consider the monetary policy rule (9) with $\omega=1$. Under rational expectations the following conditions are necessary and sufficient for a unique bounded equilibrium:

$$
0 \leqslant \phi_{\pi}<1
$$

and

$$
0 \leqslant \phi_{l}<1 \text { or } \phi_{l}>\frac{1+\beta}{1-\beta} \text {. }
$$

This is a familiar result in New Keynesian monetary economics first due to Leeper (1991). In the language of that paper, the first restriction requires monetary policy to be passive; and the second set of restrictions require fiscal policy to be active. The restrictions are referred to as the Leeper conditions. In the resulting non-Ricardian equilibria, debt has monetary consequences - indeed, the level of real debt is a state variable relevant to the determination of all model variables in equilibrium. This is the fiscal theory of the price level. Under learning, the following analogous result can be established.

Proposition 2. Consider the monetary policy rule (9) with $\omega=1$. Under learning dynamics, assuming there is only one-period debt, $\rho=0$, the following conditions are necessary and sufficient for E-Stability:

$$
0 \leqslant \phi_{\pi}<1
$$

and

$$
0 \leqslant \phi_{l}<1 \text { or } \phi_{l}>\frac{1+\beta}{1-\beta} \text {. }
$$

A sketch of the proof can be found in the technical appendix of Eusepi and Preston (forthcoming). In the case of one-period debt and contemporaneous monetary policy rule $(\omega=1)$ the conditions for expectational stability are isomorphic to those for determinacy of rational expectations equilibrium. This coincidence in requirements is only true for one-period debt. As the maturity structure of debt increases from one period - that is, as $\rho$ is increased from zero - the equivalence result breaks down. Details of debt management and fiscal policy matter for expectations stability.

\section{Calibration}

The analysis proceeds numerically. No attempt is made to fit the model to data. Instead, we choose a fairly conventional set of parameter values and study how variations in this parameter set affect expectational stability. Assuming a quarterly model the benchmark parameterization of the model follows, with departures noted at they arise in subsequent text. Household decisions: the discount factor is $\beta=0.99$; the inverse Frisch elasticity of labor supply $\gamma=1$; the inverse elasticity of intertemporal substitution of consumption $\sigma=2$; and the elasticity of demand across differentiated goods $\theta=5$. Firm decisions: nominal rigidities are determined by $\alpha=0.8 .{ }^{5}$ Fiscal policy: the structural surplus is adjusted in response to outstanding debt: $\phi_{l}=0.9$; the average level of indebtedness (in terms of debt over annual output) is $\bar{b} /(4 \bar{Y})=2$ - in line with the fiscal situation in Japan. This determines the steady-state structural surplus-to-income ratio as $\delta=\beta^{-1}(1-\beta) \bar{b} / \bar{Y}$. The steady-state consumption-to-income ratio is $s_{C}=0.8$. The autoregressive coefficients for the exogenous processes for technology and government purchases are $\rho_{Z}=\rho_{G}=0.6$. $^{6}$

The analysis now considers variations in these benchmark assumptions that are relevant to the question of expectations stability. Given a particular choice of parameters, we investigate how E-Stability is affected by varying $\phi_{\pi}$ and the average debt duration $\rho$. The configuration of monetary and

\footnotetext{
${ }^{5}$ Recall the parameter $\psi$ is determined by the choice of $\alpha$.

${ }^{6}$ The autoregressive coefficients do not play an important role in the stability analysis.
} 
fiscal polices are always consistent with the requirements for a unique bounded rational expectations equilibrium. Discussion is organized around two specifications of monetary policy: a contemporaneous interest-rate rule and an expectations-based interest-rate rule.

\section{A contemporaneous Taylor rule}

\subsection{Basic results}

Our study of stability begins with a nominal interest-rate rule that responds only to contemporaneous realizations of inflation - the monetary policy rule (9) when $\omega=1$. The policy configuration of active fiscal policy and passive monetary policy is revealed to be remarkably stable. However, instability can arise for fairly extreme values of two preference parameters: the elasticity of intertemporal substitution of consumption and the Frisch elasticity of labor supply. These extreme values have the property of minimizing the relative importance of substitution effects relative to wealth effects - a property discussed further below.

Fig. 1 plots E-Stability regions in monetary policy and debt-duration space. The three contours are distinguished by economies with differing inverse elasticities of intertemporal substitution, ranging from the extreme, $\sigma=500$, to more moderate values, $\sigma=25$ and 50, consistent with an extensive financial literature on asset pricing, but very high when compared with standard assumptions in the macroeconomics literature on business cycles. Each contour is drawn for an inverse Frisch elasticity of $\gamma=15$, with remaining parameters taking benchmark values. Regions above each contour demarcate parameter pairs $\left(\phi_{\pi}, \rho\right)$ generating expectational instability.

Consistent with Proposition 1, when there is only one-period debt, so that $\rho=0$, the Leeper conditions hold. As the average duration of debt is increased with higher values of $\rho$, the stability regions tend to contract, with more pronounced differences for large values of the inverse elasticity of intertemporal substitution of consumption. However, the effects are not monotonic: for sufficiently longduration debt, the stability regions tend to expand again, until $\rho=1$ where the Leeper are restored. Moderate maturities of debt tend to make the requirements for expectational stability more stringent.

To give a concrete example, for the largest inverse elasticity of intertemporal substitution, the largest range of monetary policies giving instability occurs around $\rho=0.7$. This corresponds to an average duration of debt roughly equal to 7 months. A value of $\rho=0.975$ would deliver an average maturity debt around 7 years, comparable to Japan. At this average debt maturity most choices of passive monetary policy are consistent with expectational stability. Choices of maturity structure between 6 and

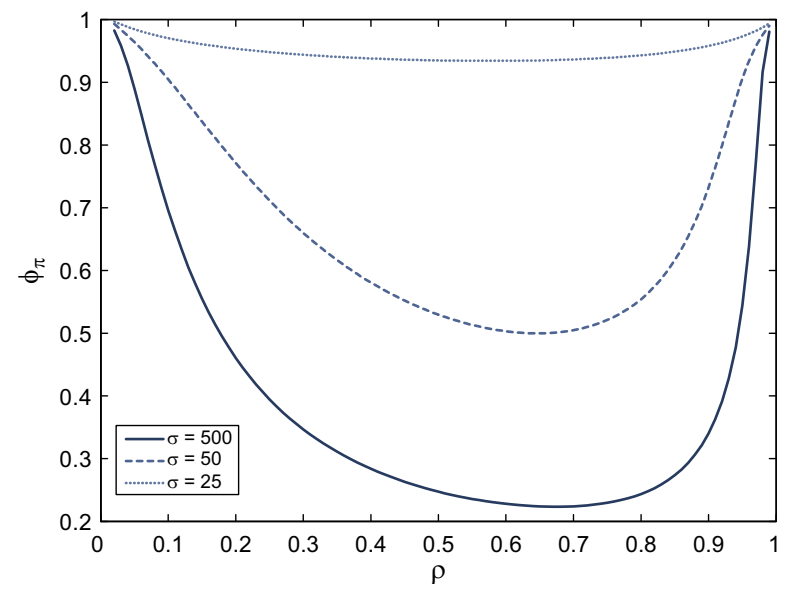

Fig. 1. The figure describes the E-stability region in the $\left(\phi_{\pi}, \rho\right)$ space. Parameters that lie above the curve deliver instability, while for parameters below the REE is E-stable. 
24 months, however, promote instability from learning dynamics. These findings are consistent with the analysis of Eusepi and Preston (2011), which considers the same model under active monetary and passive fiscal regimes.

\subsection{Inspecting the mechanism}

Instability depends on three model features. First, a monetary policy rule that responds to inflation, despite being 'passive': that is $0<\phi_{\pi}<1$. Second, a positive steady-state debt level so that variations in government liabilities have first-order effects on consumption. Third, the average duration of debt is higher than one period, so that variations in the price of bonds affects the size of public debt. We develop the importance of each model component in some detail - most subsequent results can be understood as resulting from some combination of the documented effects.

\subsubsection{A simple example}

To begin, assume that monetary policy is given by some purely exogenous process and that fiscal policy is conducted to ensure a zero steady-state level of debt: $\phi_{\pi}=\delta=0$. To further simplify, assume $\gamma \rightarrow 0$ giving perfectly elastic labor supply. Eqs. (1) and (10) become

$$
\widehat{C}_{t}=(1-\beta) \sigma^{-1} \widehat{E}_{t}^{i} \sum_{T=t}^{\infty} \beta^{T-t} \hat{w}_{T}+\beta \sigma^{-1} \widehat{E}_{t}^{i} \sum_{T=t}^{\infty} \beta^{T-t} \hat{\pi}_{T+1}
$$

and

$$
\hat{b}_{t}^{m}=\beta^{-1} \hat{b}_{t-1}^{m}-\beta^{-1} \hat{\pi}_{t}-\left(\beta^{-1}-1\right) \hat{s}_{t}
$$

under these parametric assumptions. ${ }^{7}$ Note that the evolution of debt is independent of expectations and that consumption demand has no direct dependence on debt. However, there is an indirect dependence of consumption demand on debt through expectations formation - in the rational expectations equilibrium all variables depend on debt, and learning dynamics are such that beliefs are in the neighborhood of these rational expectations.

Now consider an arbitrary increase in inflation expectations. Aggregate demand rises because of lower expected real rates. Higher aggregate demand and thus higher wages increase inflation which, in turn, decreases the real value of government debt. At the rational expectations equilibrium both wages and inflation are increasing in the level of real debt. As agents' beliefs are near rational expectations, the decline in real debt lowers inflation and wage expectations, offsetting the initial rise in beliefs; the economy converges back to its steady state. With zero steady-state debt, and a monetary policy that makes the interest rate evolve independently of endogenous variables, the economy is inherently stable.

\subsubsection{The general case}

To gain intuition in the general model, substitute (9) and (8) for the nominal interest rate and the bond price into the equations determining consumption, (1), and debt, (10), to yield

$$
\begin{aligned}
\widehat{C}_{t}= & \left(\bar{s}_{C}^{-1} \delta \hat{b}_{t-1}^{m}-\beta \sigma^{-1} \phi_{\pi} \hat{\pi}_{t}\right)+\bar{s}_{C}^{-1}(1-\beta) \widehat{E}_{t}^{i} \sum_{T=t}^{\infty} \beta^{T-t} x_{T}+\beta \sigma^{-1} \widehat{E}_{t}^{i} \sum_{T=t}^{\infty} \beta^{T-t}\left(1-\phi_{\pi} \beta\right) \hat{\pi}_{T+1} \\
& +\bar{s}_{C}^{-1} \delta \widehat{E}_{t}\left[\beta \sum_{T=t}^{\infty} \beta^{T-t} \phi_{\pi} \hat{\pi}_{T}-\beta \rho \sum_{T=t}^{\infty}(\beta \rho)^{T-t} \phi_{\pi} \hat{\pi}_{T}-\sum_{T=t}^{\infty}(\beta)^{T-t} \hat{\pi}_{T}\right]
\end{aligned}
$$

and

$$
\hat{b}_{t}^{m}=\beta^{-1} \hat{b}_{t-1}^{m}-\beta^{-1} \hat{\pi}_{t}+(1-\rho) \phi_{\pi} \hat{\pi}_{t}+(1-\rho) \rho \beta \widehat{E}_{t} \sum_{T=t}^{\infty}(\rho \beta)^{T-t} \phi_{\pi} \hat{\pi}_{T+1}-\left(\beta^{-1}-1\right) \hat{s}_{t} .
$$

\footnotetext{
${ }^{7}$ Notice that we assume agents' knowledge about the policy rule. This has no implications for E-stability in the case of a contemporaneous Taylor rule.
} 
Again consider the consequence of a rise in inflation expectations. With $\delta, \phi_{\pi}, \rho>0$ the aggregate demand and debt equations are affected by monetary and fiscal policy in three important ways. First, real debt has a direct effect on aggregate demand, as shown in the first line of (16). Holding everything else constant, as debt increases so does consumption.

Second, changes in inflation expectations and therefore nominal interest rates and the price of bonds, produce substitution and income effects. The second line gives the substitution effect. Higher inflation expectations lower real interest rates and increase demand. The third line of the consumption equation contains three distinct channels of income effect: the first term captures the direct effect of higher nominal interest rates on aggregate demand, because given debt holdings capture a higher future return. The second term captures the effects of changes in the price of the bond on aggregate demand - higher nominal interest rates imply a fall in the asset's value and therefore diminished wealth effects on demand. The third term captures the fact that inflation erodes the real value of bond holdings. The sum of these three terms is least negative when $\rho=0$. As the average duration of debt increases with $\rho$, the effects of higher anticipated inflation on demand increase monotonically from

$$
-\bar{s}_{C}^{-1} \delta\left(1-\phi_{\pi} \beta\right) \sum_{T=t}^{\infty} \beta^{T-t} \hat{\pi}_{T}
$$

to

$$
-\bar{s}_{C}^{-1} \delta \widehat{E}_{t} \sum_{T=t}^{\infty} \beta^{T-t} \hat{\pi}_{T}
$$

imparting an ever larger restraining influence. Hence changes in inflation expectations related to debt holdings appear to have a stabilizing effect on consumption - in so far as increases in inflation expectations reduce demand which in turn reduce price pressure through the Phillips curve.

\subsubsection{Debt dynamics}

Third, moving to the debt Eq. (17), with $\phi_{\pi}>0$, rising average duration of debt tends to amplify the effects of bond-price changes on the evolution of debt. These effects depend on the term

$$
(1-\rho) \rho \beta \widehat{E}_{t} \sum_{T=t}^{\infty}(\rho \beta)^{T-t} \phi_{\pi} \hat{\pi}_{T+1}
$$

which is quadratic in the parameter $\rho$. Here shifts in expected inflation are destabilizing. Increases in inflation expectations lead to an increase in debt, which weakens the stabilizing effects of higher actual inflation discussed above. Higher debt in turn increases aggregate demand, validating the rise in inflation expectations. At some intermediate value of $\rho$, say $\bar{\rho}$, the effects of shifts in inflation expectation are strongest. It follows that for $\rho$ close to $\bar{\rho}$ the instability region is largest. To think about this nonlinearity note the following. On the one hand, it is straightforward to show that, in the neighborhood of rational expectations equilibrium, the bond price becomes more sensitive to inflation expectations the greater the average duration of debt. This makes the bond issuance more sensitive to a given shift in inflation expectations. On the other hand, as the average maturity rises, the amount of debt rolled over in any given period declines - changed bond prices pertain to a smaller fraction of issued debt, captured by the term $(1-\rho)$. The former price effect tends to amplify, and the latter portfolio effect, dampen, the effect of inflation expectations on the evolution of debt. The net effects generate the nonlinearity inherent in (18). This third effect is then the source of instability in the model.

Expectations formation tends to amplify this instability. Non-Ricardian equilibria that result from the fiscal theory of the price level render debt a determinant of equilibrium outcomes of all variables. This means that forecasts of relevant prices depend on debt. That debt becomes more sensitive to inflation expectations for average maturities, makes learning the statistical properties of prices more difficult. This contributes to instability.

Central then to this result is the interaction of public debt with the effects of shifting inflation expectations on the evolution of this debt. Shifting inflation expectations only destabilize demand indirectly by changing the price at which debt is re-issued and therefore the quantity of real debt. For these effects to matter, the average maturity of debt must be such that $\rho$ close enough to $\bar{\rho}$. Indeed, 


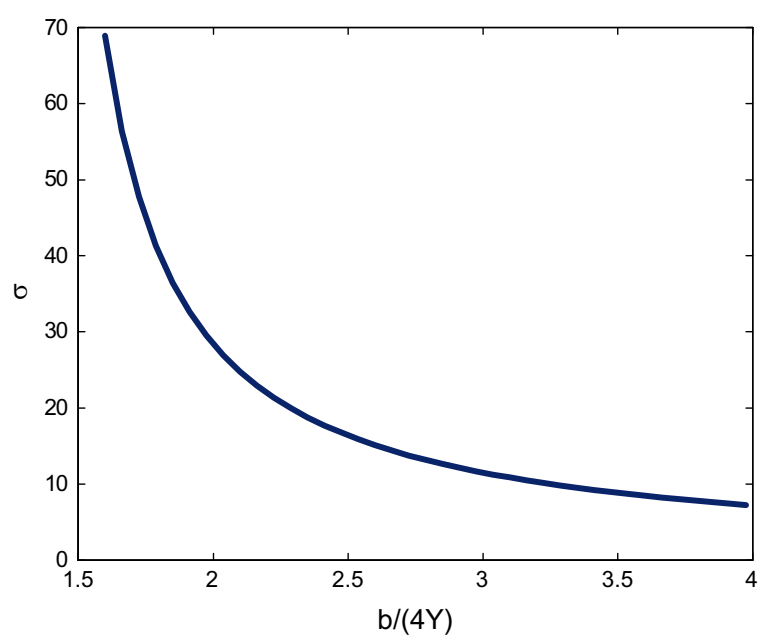

Fig. 2. The figure describes the E-stability region in the $(\sigma, \bar{b} / \bar{Y})$ space. Parameters that lie above the curve deliver instability, while for parameters below the REE is E-stable.

in the limiting cases $\rho \rightarrow 0$ and $\rho \rightarrow 1$ inflation expectations have no consequences for the evolution of real debt holdings - and the rational expectations equilibrium is expectationally stable under the Leeper conditions. For moderate values of average maturity, the bond-price effects on the level of outstanding debt are largest, which in turn delivers the largest consumption demand effects. But only if $\bar{s}_{C}^{-1} \delta>0$ - if the average level of debt were zero, there would be no wealth effects from debt on consumption demand.

\subsection{The role of intertemporal substitution and time preference}

\subsubsection{Intertemporal substitution}

The documented instability depends on the preference parameters, $\gamma$ and $\sigma$, which determine incentives to substitute labor and consumption intertemporally. To decipher the dependency, note that $\bar{s}_{C}^{-1} \delta$ is decreasing in the inverse elasticity of intertemporal substitution, inducing both smaller (destabilizing) wealth effects from holding debt and smaller (stabilizing) wealth effects from changes in expected inflation. Crucially, since $\bar{s}_{C}^{-1} \delta$ declines at a slower rate than the parameter $\sigma$, any increase in real debt has relatively stronger impact on consumption than the corresponding increase in the current nominal rate. This can be seen by inspecting the term

$$
\bar{s}_{C}^{-1} \delta \hat{b}_{t-1}^{m}-\beta \sigma^{-1} \phi_{\pi} \hat{\pi}_{t}
$$

in the first line of (16). As a consequence, the economy becomes more unstable as $\sigma$ increases. Higher values of $\gamma$ increase $\bar{s}_{C}^{-1} \delta$ and thus increase both stabilizing and de-stabilizing wealth effects from expected inflation and debt holdings. It also induces a relatively higher response of consumption to (1) changes in debt relative to the current interest rate and (2) changes in expected wages. Concerning the latter, the wage elasticity of consumption ranges from a minimum of $\sigma^{-1}$ for $\gamma \rightarrow 0$ and a maximum of $\bar{s}_{C}^{-1}(\theta-1) / \theta$ when $\gamma^{-1}=0$. Given that expected wages are positively associated with real debt, an higher consumption response to wages is destabilizing. ${ }^{8}$ Lower elasticities of labor supply widen the instability region.

Given the relative importance of the intertemporal elasticity of substitution and the level of steadystate debt, Fig. 2 plots the stability regions in $(\sigma, \bar{b} /(4 \bar{Y}))$ space, so that the debt-to-output ratio is in annual terms. Parameters that lie above the contour deliver instability, while for parameters below the

\footnotetext{
${ }^{8}$ In turn, expected profits are negatively associated with debt and thus have a stabilizing effect.
} 


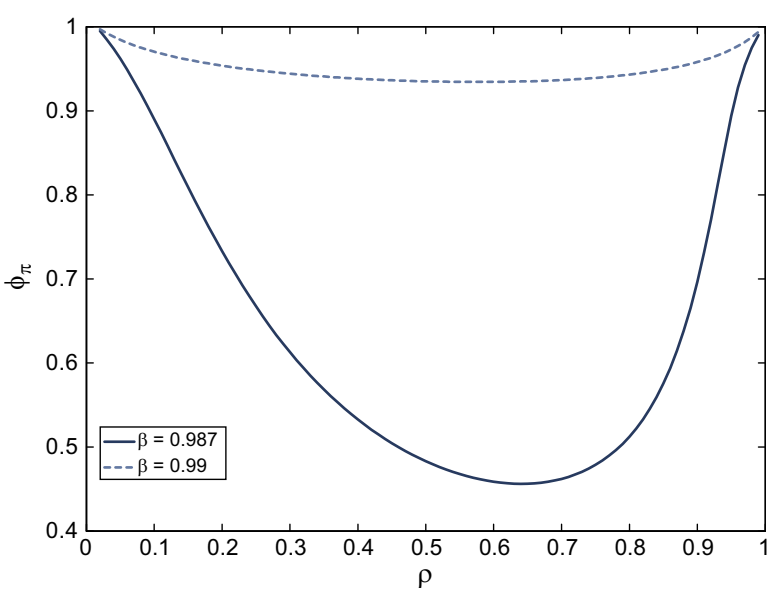

Fig. 3. The figure describes the E-stability region in the $\left(\phi_{\pi}, \rho\right)$ space. Parameters that lie above the curve deliver instability, while for parameters below the REE is E-stable.

rational expectations equilibrium is E-Stable. Elevated debt-to-output ratios render the economy less stable: as above, higher $\sigma$ or higher $\delta$ increase the term $\bar{s}_{C}^{-1} \delta \hat{b}_{t-1}^{m}-\beta \sigma^{-1} \phi_{\pi} \hat{\pi}_{t}$, magnifying the wealth effects of real debt 'net' of the current interest rate. However, even the high debt-to-output ratio of Japan requires a very low elasticity of substitution for consumption to generate expectational instability.

\subsubsection{Time preference}

Fig. 3 plots the E-Stability regions again in $\left(\phi_{\pi}, \rho\right)$ space, but examines the dependency on the discount factor $\beta$. This might be thought an important parameter as it determines the steady-state real interest rate. Benchmark parameters remain unchanged, and it is assumed that $\sigma=25$ and $\gamma=15$. Two contours are drawn for $\beta=0.99$ and $\beta=0.987$. Regions of instability occur above each contour. It is immediate that the discount rate can have a substantial effect on expectational stability. Smaller values of discount factor imply larger steady-state real interest rates. This in turn raises the financial burden of a given steady-state debt-to-income ratio. The non-monotonic effects are due to the economic effects described above. As an example of the importance of average real interest rates, an economy with $\beta=0.987$ and debt-to-output ratio of $200 \%$, has roughly the same stability properties as an economy with $\beta=0.99$ and debt-to-output ratio of $250 \%$.

The results in Figs. 1-3 depend on a number of parametric assumptions. ${ }^{9}$ Monetary and fiscal policies that are more sensitive to endogenous developments in inflation and debt engender greater instability. For example, in Fig. 1, larger values of $\phi_{l}$, which correspond to more aggressive adjustments in the structural surplus in response to variations in debt, generate larger regions of instability for a given monetary policy rule. A second dimension of importance concerns firm price-setting behavior. Greater nominal rigidities have a stabilizing effect by lowering the effects on inflation of a change in current and expected interest rates. In fact a higher value of $\alpha$ decreases the sensitivity of current inflation to current and expected demand conditions by flattening the Phillips curve. Therefore a more responsive monetary policy rule (that is a higher $\phi_{\pi}$ ) has less effect on inflation.

\subsection{A special case}

A special case of the active fiscal and passive monetary regime under examination is an interestrate policy that is purely exogenous combined with a policy for the structural surplus that is purely

\footnotetext{
${ }^{9}$ These results are not shown graphically.
} 
exogenous. Such a regime might sound to be of solely academic interest but can be argued to be of considerable historical and contemporary interest. Indeed, US monetary policy from 1942 until 1951 is most accurately described in this way. Called a "bond-price support regime", bond-prices were pegged, with fiscal policy assuming the role of active stabilization. As is well understood, the implied non-Ricardian equilibrium is unique and ensures a well-determined price level. Woodford (2001) argues that the inflation data for this period are consistent with this characterization of policy.

More recently, the US financial crises has heightened interest in such policy configurations. In many countries interest-rate policy has been subject to the constraint of the zero lower bound on nominal interest rates, while substantial fiscal stimulus has been provided with little immediate concern for the level of indebtedness. This policy configuration can reasonably be characterized as an interest-rate peg combined with exogenous structural surpluses, particularly given the substantial uncertainty about the scale, scope and duration of various policy initiatives. And even if such a characterization seems inappropriate, to the extent that agents place some probability weight on this configuration of policy, there could be important consequences for dynamics - see Bianchi (2010), Davig and Leeper (2006) and Sims (2011). As such it is worth exploring the stabilization properties of this kind of policy regime, and specifically their dependency on the maturity structure of debt.

Proposition 2 establishes that this policy configuration is remarkably stable in the case of one-period debt - the requirements for expectational stability are identical to those for a unique bounded rational expectations equilibrium. The Leeper conditions hold. This is entirely consistent with the results above which show that more active fiscal and monetary rules can lead to instability. While analytical results could not be determined for the general case of multiple-maturity debt, a numerical study of the conditions for expectational stability permits the following claim.

Claim 3. Consider the monetary policy rule determined by

$$
\phi_{\pi}=0
$$

and the set of parameter values

$$
\begin{aligned}
& \beta \in[0.95,0.99] ; \quad \theta \in[4,100] ; \gamma=[0.01,100] ; \phi_{l} \in[0,0.99] \\
& \alpha=[0.01,0.99] ; \quad \sigma \in[1,2000] ; \quad \bar{b} / 4 \bar{Y} \in[0,4] ; \rho \in[0,1] .
\end{aligned}
$$

Then the rational expectations equilibrium is found to be E-Stable for all indicated combinations of parameter values.

Despite the lack of formal proof, this numerical evidence strongly suggests that a nominal interestrate peg exhibits remarkable stability in the case of multiple-maturity debt. As such, switching to an active fiscal policy rule which delivers aggressive fiscal stimulus when the interest rate is at the zero lower bound can be an effective policy option to prevent a deflationary spiral.

There are two caveats to this recommendation. First, the stability analysis has only local validity; that is the stability results hold provided agents' expectations are sufficiently close to rational expectations. A switch from a Ricardian regime with active monetary policy to an active fiscal regime coupled with an interest-rate peg requires a significant adjustment in public expectations. The success of such a policy is likely determined by the communication strategy followed by the monetary and fiscal authority, and their credibility in following announced plans. Second, we focus on rational expectations equilibria where the policy regime remains in place indefinitely. As documented in Davig and Leeper (2006) for the US, policy regime switches are the norm. A switch to an active fiscal regime in response to hitting the zero lower bound would likely be temporary in nature. An extension of the stability analysis to regime switches is left for further research, but the tools for such inquiry can be found in Branch et al. (2008) which studies the E-Stability properties of regime switching models using learning models where only one-period-ahead expectations matter.

\section{Forward-looking policy rule}

Now consider the policy rule (9) with $\phi_{\pi}>0$ and $\omega=0$. When agents must learn about the conduct of policy, Eusepi and Preston (forthcoming) show that expectations-based interest-rate rules can 


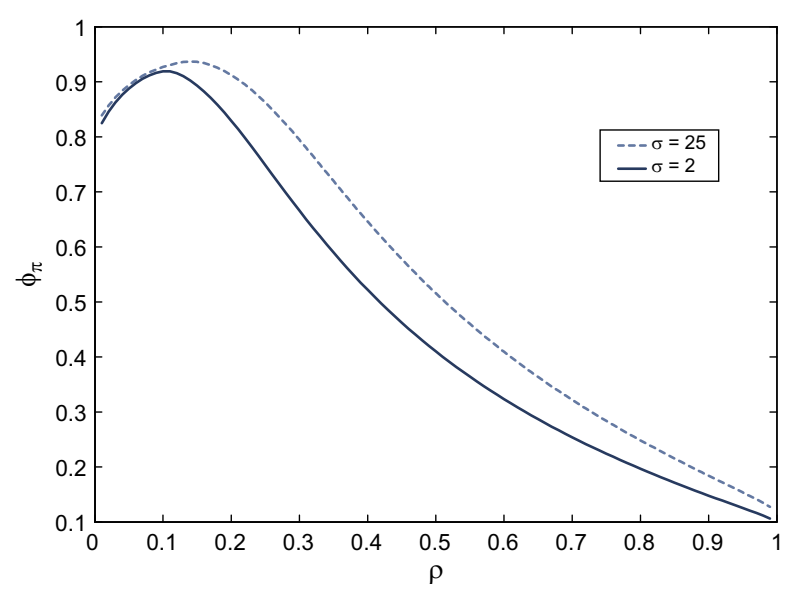

Fig. 4. The figure describes the E-stability region in the $\left(\phi_{\pi}, \rho\right)$ space. Parameters that lie above the curve deliver instability, while for parameters below the REE is E-stable.

deliver instability even when fiscal policy is active. ${ }^{10}$ Here we explore the consequences of different average maturities of debt for these insights. As before, the analysis is organized by examining specific features of household preferences - the role of intertemporal substitution of consumption and leisure and the discount factor.

We also study the role of central bank communication in the stability analysis. Eusepi and Preston (2010a) and Eusepi and Preston (forthcoming) analyze implications of agents having differing degrees of information about the conduct of monetary policy. The case of agents having no knowledge of the policy rule employed by monetary authority is called "no communication". Households and firms must infer the statistical properties of nominal interest-rate policy from historical realizations of this variable and the state. In contrast, the case when agents know the monetary policy rule is called "communication". The import of this assumption is that households and firms can make policy-consistent forecasts. Beliefs about the joint probability distribution of inflation and nominal interest rates is consistent with the restriction implied by the monetary policy rule. This permits more accurate forecasts, which is conducive to macroeconomic stability. ${ }^{11}$

\subsection{The case of no communication}

In the case of no communication about monetary policy, agents forecast future interest rates according to the belief structure described in Section 3. With expectations-based policy rules, lack of knowledge of the policy rule can be a source of instability which is not related to wealth effects stemming from fiscal policy or debt dynamics. Instead, instability arises from a failure of the central bank to manage expectations. Because interest-rate policy depends on inflation expectations, and inflation expectations exhibit sluggish adjustment, the central bank responds slowly to changing economic conditions; and private agents themselves respond with a delay to changes in monetary policy because of learning dynamics. As a result, the central bank responds too much and too late, creating instability in aggregate demand. This channel of instability is documented in Eusepi and Preston (forthcoming). It is also an example of Friedman (1968) 's long and variable lags as a source of

\footnotetext{
10 Preston $(2006,2008)$ also discusses a range of difficulties that expectations-based instrument rules for the nominal interest rate pose for stabilization policy under learning dynamics.

11 The analysis extends the treatments of Eusepi and Preston (2010a, forthcoming) by considering active fiscal and passive monetary policy in an environment of multiple maturity debt, and properly accounting for the endogeneity of labor supply decisions on optimal consumption - see Eusepi and Preston (2011) for a discussion of the latter.
} 


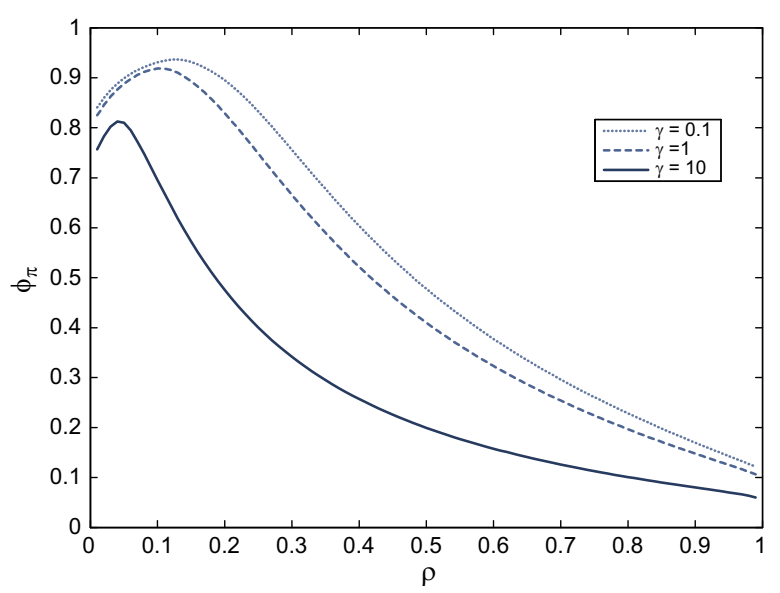

Fig. 5. The figure describes the E-stability region in the $\left(\phi_{\pi}, \rho\right)$ space. Parameters that lie above the curve deliver instability, while for parameters below the REE is E-stable.

macroeconomic instability, and the basis of his criticism of procedures to implement monetary policy using interest-rate rules.

Fig. 4 shows the E-Stability region in the $\left(\phi_{\pi}, \rho\right)$ space for two different economies distinguished by $\sigma=2$ and 25. Parameters pairs that lie above the curve deliver instability, while for parameter pairs below the rational expectations equilibrium is E-Stable. It is immediate that the overall instability region is considerably wider when compared with an economy with a contemporaneous Taylor rule as in Fig. 1. The stability contours of Fig. 4 are strictly below those of Fig. 1. The forecast-based interestrate rule has an additional source of instability coming from the central banks' failure to stabilize aggregate demand.

In contrast to the previous section, an higher average duration of debt monotonically widens the instability region. For values of $\rho$ near unity, monetary policy must exhibit almost no sensitivity to variations in inflation - interest rates are required to be exogenous to deliver stability. Consistent with proposition 2 of Eusepi and Preston (forthcoming), even an economy with one-period debt displays instability for some combination of parameter values. The instability result reflects the different mechanism that is at work in the case of expectations-based nominal interest-rate rules when compared with contemporaneous interest-rate rules. Longer debt maturity implies that 'unanchored' expectations about future interest rates have a larger impact on the economy through variations in bond prices which in turn affects the evolution of aggregate demand.

The intuition can again be described in terms of Eq. (16), where now we assume agents have no knowledge about the monetary policy rule. Expectations about the nominal rate affect consumption according to the term

$$
-\beta \sigma^{-1} \widehat{E}_{t}^{i} \sum_{T=t}^{\infty} \beta^{T-t} \hat{\boldsymbol{l}}_{T}+\overline{\boldsymbol{s}}_{C}^{-1} \delta \beta \widehat{E}_{t}\left[\sum_{T=t}^{\infty} \beta^{T-t} \hat{\boldsymbol{l}}_{T}-\rho \sum_{T=t}^{\infty}(\beta \rho)^{T-t} \hat{\boldsymbol{l}}_{T}\right] .
$$

From this relation, higher $\rho$ increases the relative importance of substitution effects (the first term), which are the source of aggregate demand instability - agents fail to project accurately future real interest rates. ${ }^{12}$ Interestingly, the source of instability is not fiscal policy per se, but agents' lack of information about the monetary policy rule. Monetary policy remains important even if it is passive!

Fig. 4 reveals two other insights. First, instability arises for parameter values which are consistent with a range of evidence using both household and aggregate consumption data: for example, inverse

\footnotetext{
${ }^{12}$ Notice that with $\rho=1$ debt no longer depends on expectations. The source of instability lies on the dynamics of aggregate demand only.
} 
elasticities of intertemporal substitution equal to 2 - see Hall (2009) and Basu and Kimball (2000). Second, lower elasticities of intertemporal substitution of consumption assist stability under learning dynamics. While higher values of inverse elasticity, $\sigma$, tend to raise the importance of wealth effects of debt holdings on aggregate demand (as discussed above), they also decrease the sensitivity of aggregate consumption to expected real interest rates. Because these forecasted real interest rates are the dominant source of instability, reducing the elasticity of intertemporal substitution promotes E-Stability under forecast-based instrument rules - see again (19).

Fig. 5 also shows the E-Stability region in the $\left(\phi_{\pi}, \rho\right)$ space for different values of the Frisch elasticity of labor supply, assuming $\sigma=2$. As in the model with contemporaneous policy rule, a lower elasticity of labor supply enlarges the region of instability. Finally it can be shown that, as in the previous section, higher nominal rigidities stabilize the economy.

\subsection{The case of communication}

We now consider the case of communication of the monetary policy rule. This means agents can make policy-consistent interest-rate forecasts. Beliefs are as specified in Section 3 with the exception of nominal interest-rate forecasts. Given a projected path for inflation, interest-rate forecasts are determined implicitly by the monetary policy rule. That is, forecast paths for interest-rates in any period $t$ are computed as

$$
\widehat{E}_{t} i_{T}=\phi_{\pi} \widehat{E}_{t} \pi_{T+1}
$$

for all $T \geqslant t$. Communication improves the stabilization properties of forecast-based instrument rules by providing a more accurate forecast of future real interest rates.

Fig. 6 shows the E-Stability region in the $\left(\phi_{\pi}, \rho\right)$ space for three economies distinguished by households' inverse elasticity of intertemporal substitution: $\sigma=25,35$ and 45. Again, regions of expectational instability lie above each contour. Comparing Fig. 6 to Fig. 4 reveals that the regions of expectational stability rise at all average maturities of debt - note the $\sigma=25$ contours in each figure. Economies with long-maturity debt are much more stable under central bank communication which reduces one dimension of uncertainty.

Further insights emerge from comparison of Figs. 6 and 1 (the case of a simple Taylor rule). Under expectations-based instrument rules, instability occurs even for economies with one-period debt only. Debt depends on expected inflation given a forward-looking policy rule. This imparts a destabilizing effect on expectations.

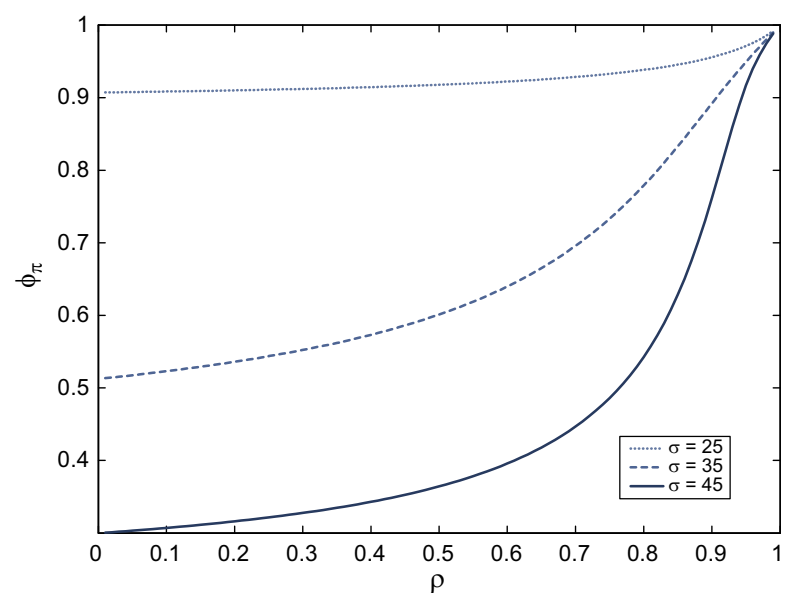

Fig. 6. The figure describes the E-stability region in the $\left(\phi_{\pi}, \rho\right)$ space. Parameters that lie above the curve deliver instability, while for parameters below the REE is E-stable. 


\section{The role of financial market expectations}

The belief structure laid out in Section 3 has the property that the no-arbitrage condition (7) is satisfied in all periods of the household's decision horizon. Agent's beliefs determine a forecast of the future sequence of one-period interest rates $\left\{\hat{\imath}_{T}\right\}$ from which the multiple-maturity bond portfolio is priced using (8). Because the bond pricing equation is an implication of the no-arbitrage condition, relation (7) is necessarily satisfied at all dates.

An alternative approach would be to suppose households forecast future bond prices directly using some econometric model, which combined with (7) would determine a no-arbitrage consistent forecast path for the one-period interest rate. While these two approaches are equivalent under rational expectations, they will in general differ under arbitrary assumptions on belief formation. Indeed, consider augmenting the beliefs structure (14) with an additional dependent variable in the price of the multiple-maturity bond portfolio. Then absent the restrictions imposed by a rational expectations equilibrium analysis - which would impose the specific restriction that beliefs are consistent with no-arbitrage - the augmented belief structure will permit very general relationships between the bond price and the period interest rate - there is no reason to suppose that the implied forecast would satisfy (7).

We now consider the consequences of this alternative formulation of financial market beliefs. This is called unanchored financial market expectations since one less optimality condition is exploited relative to earlier analysis - specifically, the transversality condition. Formally these assumptions imply two changes to the model. The equations for the bond price and consumption, (8) and (1), are replaced by the no-arbitrage condition (7) which determines the asset price as

$$
\widehat{P}_{t}^{m}=-\hat{l}_{t}+\rho \beta \widehat{E}_{t} \widehat{P}_{t+1}^{m}
$$

and the consumption decision rule

$$
\begin{aligned}
\widehat{C}_{t}= & \bar{s}_{C}^{-1} \delta\left(\hat{b}_{t-1}^{m}-\hat{\pi}_{t}+\rho \beta \widehat{P}_{t}^{m}\right)-\beta\left(\sigma^{-1}-\bar{s}_{C}^{-1} \delta\right) \hat{\imath}_{t}-\widehat{E}_{t} \\
& \times \sum_{T=t}^{\infty} \beta^{T-t}\left[\beta\left(\sigma^{-1}-\bar{s}_{C}^{-1} \delta\right)\left(\beta\left(\rho \beta \widehat{P}_{T+2}^{m}-\widehat{P}_{T+1}^{m}\right)-\hat{\pi}_{T+1}\right)\right]+\widehat{E}_{t} \sum_{T=t}^{\infty} \beta^{T-t}\left[\bar{s}_{C}^{-1}(1-\beta) x_{T}\right]
\end{aligned}
$$

obtained by substitution for nominal interests rates by (7) in (1) - this ensures interest-rate forecasts are those consistent with bond-price forecasts given (7). All other relations remain unchanged, with

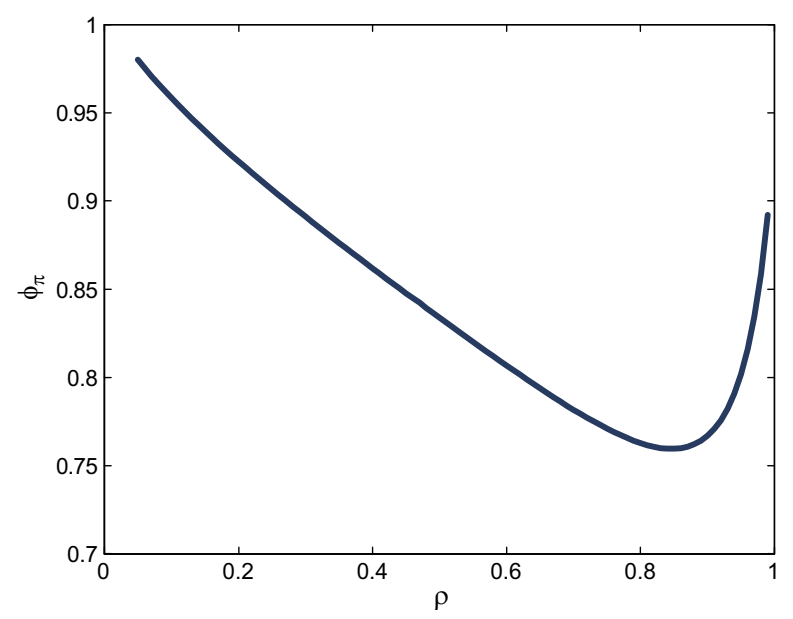

Fig. 7. The figure describes the E-stability region in the $\left(\phi_{\pi}, \rho\right)$ space. Parameters that lie above the curve deliver instability, while for parameters below the REE is E-stable. 
the exception of beliefs where the bond price $\widehat{P}_{t}^{m}$ replaces nominal interest rates $\hat{\imath}_{t}$ as a dependent variable in (14) to give

$$
\left[\begin{array}{c}
\hat{\pi}_{t} \\
\widehat{P}_{t}^{m} \\
\hat{w}_{t} \\
\hat{\Gamma}_{t} \\
\hat{s}_{t} \\
b_{t}^{m}
\end{array}\right]=\Omega_{0}+\Omega_{1}\left[\begin{array}{c}
\hat{\pi}_{t-1} \\
\widehat{P}_{t-1}^{m} \\
\hat{w}_{t-1} \\
\hat{\Gamma}_{t-1} \\
\hat{s}_{t-1} \\
b_{t-1}^{m}
\end{array}\right]+\Omega_{t, 2}\left[\begin{array}{c}
\widehat{G}_{t-1} \\
\widehat{Z}_{t-1}
\end{array}\right]+e_{t}
$$

Fig. 7 shows the E-Stability region in the $\left(\phi_{\pi}, \rho\right)$ space for the case of unanchored financial expectations. Monetary policy is again given by a rule with $\omega=1$, implying interest rates respond only to current inflation. Here we set $\sigma=2$ and $\gamma=1$ - parameter values that generated little instability in the case of a contemporaneous interest rate rule. It is immediate that the specification of financial market expectations is important for macroeconomic stability. The figure reveals an humped-shaped relation between debt duration and the stability region. Intermediate values of debt enlarge the instability area, while short-term and long-term maturities deliver a wider stability set.

The intuition for this result is similar to the discussion in the Section 6. However, the instability region is much wider. Unanchored financial expectations limit the influence of nominal interest-rate policy on aggregate demand. This can been seen from the aggregate demand relation (20). When the average maturity of debt is unity, so that $\rho=0$, the model is isomorphic to the model under anchored financial expectations. Here the multiple-maturity debt portfolio collapses to one-period bonds, which satisfy $\widehat{P}_{t}^{s}=\widehat{P}_{t}^{m}=-\hat{l}_{t}$. Even though agents only have a forecasting model in the bond price this is equivalent to forecasting the period interest rate when there is only one-period debt. As the average maturity structure of debt increases this equivalence breaks down. An implication is that only current interest rates have a direct effect of aggregate demand. This substantially weakens the restraining influence of future interest-rate policy on aggregate demand. Finally, instability occurs also in the case of $\rho=1$. This is because, even if debt does not depend on expectations, the price of debt does. It is determined by the no-arbitrage condition

$$
\widehat{P}_{t}^{m}=-\hat{l}_{t}+\widehat{E}_{t} \rho \beta \widehat{P}_{t+1}^{m}
$$

and it thus depends on expected future prices.

\section{Alternative models of learning}

Many recent papers have proposed analyses of learning dynamics in the context of models where agents solve infinite-horizon decision problems, but without requiring that agents make forecasts more than one period into the future. In these papers, agents' decisions depend only on forecasts of future variables that appear in Euler equations used to characterize rational expectations equilibrium. Important contributions include Bullard and Mitra (2002) and Evans and Honkapohja (2003). Of most relevance to the present study is Evans and Honkapohja (2007) which similarly studies the interaction of monetary and fiscal policy, but in a model of learning dynamics in which only one-period-ahead expectations matter to expenditure and pricing plans of households and firms. The following section replicates part of their analysis in the context of the model developed here, and contrasts the resulting findings with those of Section 6.

Since the optimal decision rules for households and firms presented in Section 2 are valid under arbitrary assumptions on expectations formation, they are valid under the rational expectations assumption. Application of this assumption implies the law of iterated expectations to hold for the aggregate expectations operator and permits simplification of relations (10) and (11) in the paper to the following aggregate Euler equation and Phillips curve: ${ }^{13}$

\footnotetext{
13 See Preston (2005a,b) for a detailed discussion.
} 


$$
\begin{aligned}
& \widehat{C}_{t}=E_{t} \widehat{C}_{t+1}-\left(\hat{\imath}_{t}-E_{t} \hat{\pi}_{t+1}\right) \\
& \hat{\pi}_{t}=\psi\left(\hat{w}_{t}-\widehat{Z}_{t}\right)+\beta E_{t} \hat{\pi}_{t+1}
\end{aligned}
$$

where $E_{t}$ denotes rational expectations. Under learning dynamics, with only one-period-ahead expectations, it is assumed that aggregate demand and supply conditions are determined by

$$
\begin{aligned}
& \widehat{C}_{t}=\widehat{E}_{t} \widehat{C}_{t+1}-\left(\hat{l}_{t}-\widehat{E}_{t} \hat{\pi}_{t+1}\right) \\
& \hat{\pi}_{t}=\psi\left(\hat{w}_{t}-\widehat{Z}_{t}\right)+\beta \widehat{E}_{t} \hat{\pi}_{t+1} .
\end{aligned}
$$

One other model equation depends on expectations: the no-arbitrage condition. Remaining within the spirit of the one-period expectation approach, proceed under the assumption that financial expectations are unanchored so that the restriction

$$
\hat{\imath}_{t}=-\widehat{E}_{t}\left(\widehat{P}_{t}^{m}-\bar{\pi}^{-1} \rho \beta \widehat{P}_{t+1}^{m}\right)
$$

determines the price of multiple-maturity debt, given expectations about this price next period, and current nominal interest rates. This replaces

$$
\widehat{P}_{t}^{m}=-\widehat{E}_{t} \sum_{T=t}^{\infty}(\rho \beta)^{T-t} \hat{\imath}_{T}
$$

which of course requires forecasts of nominal interest rates into the indefinite future. All remaining equations, being independent of expectations, are as before.

The model is closed with a description of beliefs. Under the reformulated model, wages, dividends, taxes and nominal interest rates need not be forecasted. However, spending decisions now depend on a forecast of next-period aggregate consumption. Assume, for analytical simplicity, that agent's beliefs are given by the model

$$
\left[\begin{array}{c}
\widehat{C}_{t} \\
\hat{\pi}_{t} \\
\hat{b}_{t}^{m} \\
\widehat{P}_{t}^{m}
\end{array}\right]=\Omega_{t, 0}+\Omega_{1} \hat{b}_{t-1}^{m}+\Omega_{2}\left[\begin{array}{c}
\widehat{G}_{t-1} \\
\widehat{Z}_{t-1}
\end{array}\right]+e_{t}
$$

with appropriate redefinition of the dimensions of $\Omega_{0}, \Omega_{1}$ and $\Omega_{2}$.

It is immediate that this model represents a fundamentally different approach to decision making. Taxes and debt holdings have no direct relevance to economic decisions - and specifically the details of debt-management policy have no consequences for household spending plans. These model features only matter to the extent that they shape the evolution of beliefs in the neighborhood of rational expectations equilibrium. This turns out to be important.

In the one-period-ahead forecasting model, defined by replacing relations (1), (2) and (8) with (21), (22) and (7) in the benchmark model, the following stability result obtains.

Proposition 4. Consider the monetary policy rule (9) with $\omega=1$. Necessary and sufficient conditions for expectational stability are

$$
0 \leqslant \phi_{\pi}<1
$$

and

$$
0 \leqslant \phi_{l}<1 \text { or } \phi_{l}>\frac{1+\beta}{1-\beta} .
$$

This generalizes one specific result of the Evans and Honkapohja (2007) analysis to a model with nominal rigidities. ${ }^{14}$ When only one-period-ahead expectations matter, the Leeper conditions are necessary and sufficient to rule out expectations-driven instability. In contrast, in a model of optimal decisions,

\footnotetext{
${ }^{14}$ The proof is available on request.
} 
these conditions obtain only if the average maturity of debt is equal to unity. Absent this property, the analysis of this paper suggests a smaller menu of policies is consistent with expectations stabilization. Debt management policy can represent an important constraint on the design of monetary policy.

\section{Conclusion}

This paper applied the framework developed in Eusepi and Preston (2011) to examine the consequences of the scale and composition of the public debt in policy regimes in which monetary policy is 'passive' and fiscal policy 'active'. This configuration of policy is argued to be of both historical and contemporary interest, in economies such as the US and Japan. The central result is that higher average levels and moderate average maturities of debt can induce macroeconomic stability for a range of policies specified as simple rules. In contrast, very short and long average debt maturities are often more conducive to stability. However, regardless of the scale and composition of debt, interest-rate pegs combined with active fiscal policies almost always ensure macroeconomic stability. This suggests that in periods where the zero lower bound on nominal interest rates is a relevant constraint on policy design, a switch in fiscal regime is desirable.

\section{Acknowledgments}

This paper was prepared for the 23rd NBER-TRIO conference. The authors thank Eric Leeper for many valuable conversations. Two anonymous referees and our discussant Kosuke Aoki are also thanked for valuable comments. The views expressed in the paper are those of the authors and are not necessarily reflective of views at the Federal Reserve Bank of New York or the Federal Reserve System. The usual caveat applies.

\section{References}

Basu, S., Kimball, M., 2000. Long Run Labor Supply and the Elasticity of Intertemporal Substitution for Consumption, mimeo, University of Michigan.

Bianchi, F., 2010. Regime Switches, Agents' Beliefs, and Post-World-War II U.S. Macroeconomic Dynamics, unpublished, Duke University.

Branch, W.A., Davig, T., McGough, B., 2008. Adaptive Learning in Regime-Switching Models, unpublished, University of California, Irvine.

Bullard, J., Mitra, K., 2002. Learning about monetary policy rules. J. Monet. Econ. 49 (6), 1105-1129.

Clarida, R., Gali, J., Gertler, M., 1999. The science of monetary policy: A new Keynesian perspective. J. Econ. Lit. 37, $1661-1707$.

Davig, T., Leeper, E., 2006. Fluctuating Macro Policies and the Fiscal Theory. In: Acemoglu, D., Rogoff, K., Woodford, M. (Eds.). NBER Macroeconomics Annual.

Eusepi, S., Preston, B., 2010a. Central bank communication and macroeconomic stabilization. Amer. Econ. J.: Macroecon. 2, 235271.

Eusepi, S., Preston, B., forthcoming. Debt, Policy Uncertainty and Expectations Stabilization. J. Europ. Econ. Assoc.

Eusepi, S., Preston, B., 2011. The Maturity Structure of Debt, Monetary Policy and Expectations Stabilization, unpublished, Columbia University.

Evans, G.W., Honkapohja, S., 2001. Learning and Expectations in Economics. Princeton University Press, Princeton.

Evans, G.W., Honkapohja, S., 2003. Expectations and the stability problem for optimal monetary policies. Rev. Econ. Stud. 70 (4), 807-824.

Evans, G.W., Honkapohja, S., 2007. Policy interaction, learning and the fiscal theory of prices. Macroecon. Dynam. 11, 665-690.

Friedman, M., 1968. The role of monetary policy. Amer. Econ. Rev. 58 (1), 1-17.

Hall, R., 2009. Reconciling Cyclical Movements in the Marginal Value of Time and the Marginal Product of Labor," mimeo, Stanford University.

Kreps, D., 1998. Anticipated utility and dynamic choice. In: Jacobs, D., Kalai, E., Kamien, M. (Eds.), Frontiers of Research in Economic Theory. Cambridge University Press, Cambridge, pp. 242-274.

Leeper, E., 1991. Equilibria under 'Active' and 'Passive' monetary and fiscal policies. J. Monet. Econ. 27, $129-147$.

Marcet, A., Sargent, T.J., 1989a. Convergence of least-squares learning in environments with hidden state variables and private information. J. Polit. Economy, 1306-1322.

Marcet, A., Sargent, T.J., 1989b. Convergence of least squares learning mechanisms in self-referential linear stochastic models. J. Econ. Theory (48), 337-368.

Preston, B., 2005a. Adaptive Learning in Infinite Horizon Decision Problems, unpublished, Columbia University.

Preston, B., 2005b. Learning about monetary policy rules when long-horizon expectations matter. Int. J. Central Banking 1 (2), 81-126.

Preston, B., 2006. Adaptive learning, forecast-based instrument rules and monetary policy. J. Monet. Econ. 53, 507-535.

Preston, B., 2008. Adaptive learning and the use of forecasts in monetary policy. J. Econ. Dynam. Control 32 (4), 2661-3681. 
Sargent, T.J., 1999. The Conquest of American Inflation. Princeton University Press.

Sargent, T.J., Wallace, N., 1975. Rational expectations, the optimal monetary instrument, and the optimal monetary supply rule. J. Polit. Economy 83, 241-254.

Sims, C., 2011. Model With Fiscal-Driven Inflation Expectations, unpublished, Princeton University.

Woodford, M., 1998. Public Debt and the Price Level, unpublished manuscript, Columbia University.

Woodford, M., 2001. Fiscal requirements of price stability. J. Money, Credit Banking 33, 669-728.

Woodford, M., 2003. Interest and Prices: Foundations of a Theory of Monetary Policy. Princeton University Press.

Yun, T., 1996. Nominal price rigidity, money supply endogeneity, and business cycles. J. Monet. Econ. 37, 345-370. 